
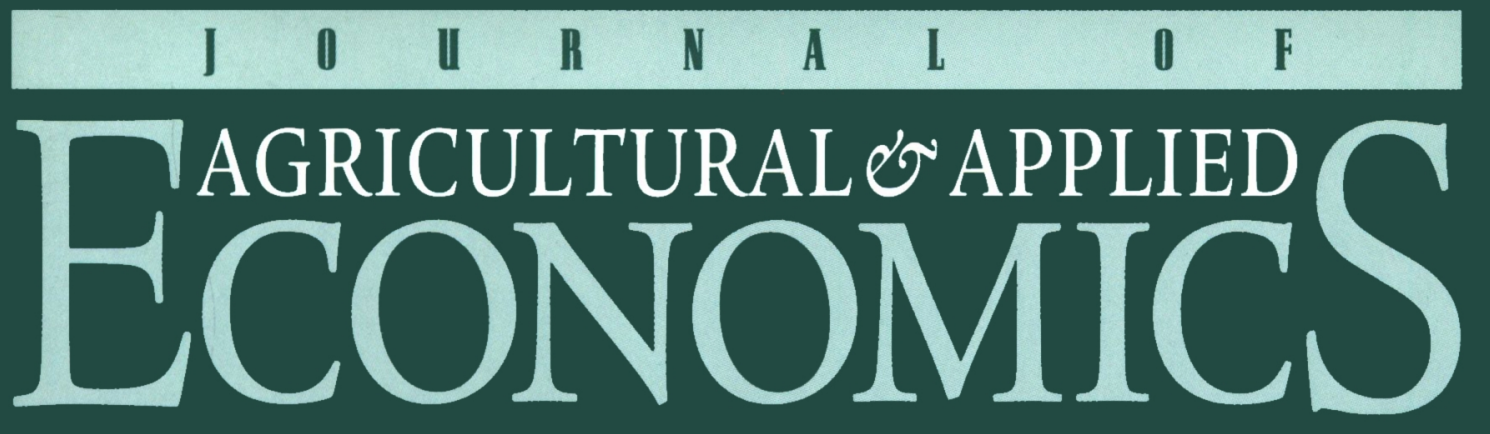

\title{
VOLLIME 37
}

\section{December 2005}

NUMBER 3

\section{Articles}

Experimental Evidence on Willingness to Pay for Red Meat Traceability in the United States, Canada, the United Kingdom, and Japan / David L. Dickinson and DeeVon Bailey

Technology Adoption and Off-Farm Household Income: The Case of Herbicide-Tolerant Soybeans / Jorge Fernandez-Cornejo, Chad Hendricks, and Ashok Mishra

Do Antibiotics Reduce Production Risk for U.S. Pork Producers? / Xuanli Liu, Gay Y. Miller and Paul E. McNamara

Factors Affecting Perceived Improvements in Environmental Quality from Precision Farming / Sherry L. Larkin, Larry Perruso, Michele C. Marra, Roland K. Roberts, Burton C. English, James A. Larson, Rebecca L. Cochran and Steven W. Martin

Evidence on the Amenity Value of Wetlands in a Rural Setting / Okmyung Bin and Stephen Polasky

Modeling Beef Quality Heterogeneity / Jayson L. Lusk and F. Bailey Norwood

Estimating Indirect Production Functions with a More General Specification: An Application of the Lewbel Model / Christiana E. Hilmer and Matthew T. Holt

Measuring the Impact of Externalities on College of Agriculture Teaching Evaluations $/$ Ronald A. Fleming, Ernest F. Bazen, and Michael E. Wetzstein

Consumer Willingness to Pay for "Second-Generation" Genetically Engineered Products and the Role of Marketing Information / Matthew C. Rousu, Daniel C. Monchuk, Jason F. Shogren and Katherine M. Kosa

Exploring Horticultural Employees' Attitudes towards Their Jobs: A Qualitative Analysis Based on Herzberg's Theory of Job Satisfaction / Vera Bitsch and Michael Hogberg

Willingness to Pay for Information Programs about E-commerce: Results from a Convenience Sample of Rural Louisiana Businesses / Susan Watson, O. John Nwoha, Gary Kennedy, and Kenneth Rea

Effects of Federal Risk Management Programs on Optimal Acreage Allocation and Nitrogen Use in a Texas Cotton-Sorghum System / Sangtaek Seo, Paul D. Mitchell, and David J. Leatham

Willingness to Pay for Genetically Modified Oil, Cornflakes, and Salmon: Evidence from a U.S. Telephone Survey / Naoya Kaneko and Wen S. Chern 


\title{
EDITORIAL STAFF
}

\author{
Editor \\ Henry Kinnucan \\ Auburn University \\ Associate Editors \\ Dragan Miljkovic \\ North Dakota State University \\ Øystein Myrland \\ University of Tromsø, Norway
}

Editorial Council

\author{
Darrell J. Bosch \\ Virginia Tech \\ Keith H. Coble \\ Mississippi State University \\ David L. Debertin \\ University of Kentucky \\ Kevin C. Dhuyvetter \\ Kansas State University \\ Cesar L. Escalante \\ University of Georgia \\ Diane Hite \\ Auburn University \\ Neal H. Hooker \\ The Ohio State University \\ Scott H. Irwin \\ University of Illinois
}

\author{
P. Lynn Kennedy \\ Louisiana State University \\ Maria L. Loureiro \\ IDEGA-Universidade de Santiago \\ de Compostela, Spain \\ Daniel V. Rainey \\ University of Arkansas \\ Daryll E. Ray \\ University of Tennessee \\ Jeffrey J. Reimer \\ University of Wisconsin \\ Cathy A. Roheim \\ University of Rhode Island \\ Loren W. Tauer \\ Cornell University
}

\section{EDITORIAL POLICY}

The Journal of Agricultural and Applied Economics (JAAE) provides a forum for creative and scholarly work in agricultural economics and related areas. Contributions on methodology and applications in business, extension, research, and teaching phases of agricultural and applied economics are equally encouraged. Submitted manuscripts are subject to peer review for publication consideration. Submission of critiques or comments on $J A A E$ articles are welcomed.

\section{EDITORIAL COMMUNICATIONS}

The editorship of the $J A A E$ will change with Volume 37. Please send all manuscript submissions and editorial correspondence for manuscripts submitted after June 30, 2004 to Henry W. Kinnucan, Editor, $J A A E$, Department of Agricultural Economics and Rural Sociology, 213 Comer Hall, Simmons Drive, Auburn University, Auburn, AL 36849-5401. Phone: (334) 844-5614; Fax: (334) 844-5639; Email: JAAE@auburn.edu.

The Journal of Agricultural and Applied Economics (ISSN 1074-0708) is published in April, August, and December by the Southern Agricultural Economics Association (SAEA). Visit our worldwide web site at http://www.agecon.uga.edu/ jaae/jaae.htm.

Copyright (C) 2005 by the Southern Agricultural Economics Association. Any article or other material published in the $J A A E$ may not be resubmitted for publication or republished elsewhere in full or in part without the written permission of the editor. 


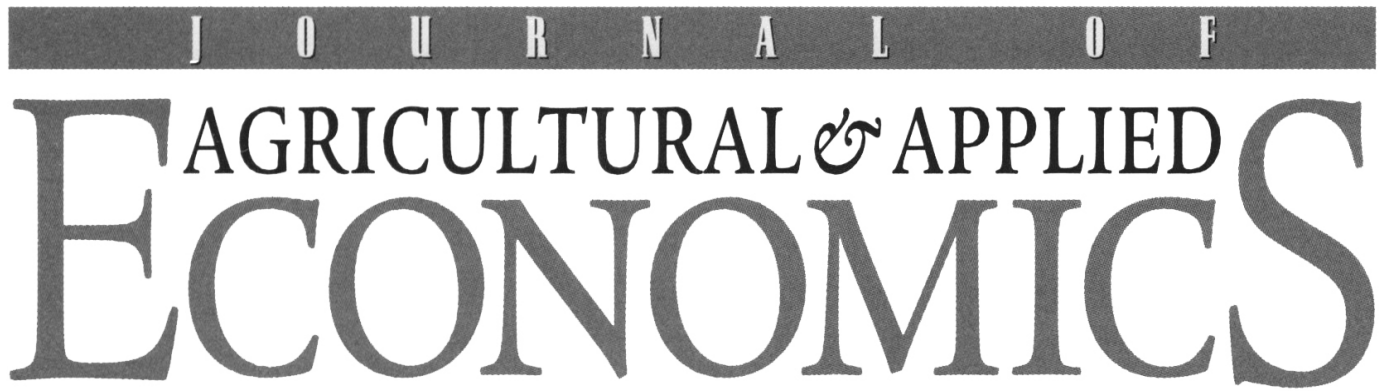

VOLUME $\overline{37}$

IECEMBER 2005

NUMBER 3

\section{Articles}

Experimental Evidence on Willingness to Pay for Red Meat Traceability in the United States, Canada, the United Kingdom, and Japan / David L. Dickinson and DeeVon Bailey ........ 537

Technology Adoption and Off-Farm Household Income: The Case of Herbicide-Tolerant

Soybeans / Jorge Fernandez-Cornejo, Chad Hendricks, and Ashok Mishra . .

Do Antibiotics Reduce Production Risk for U.S. Pork Producers? / Xuanli Liu, Gay Y. Miller

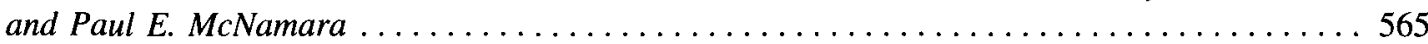

Factors Affecting Perceived Improvements in Environmental Quality from Precision Farming / Sherry L. Larkin, Larry Perruso, Michele C. Marra, Roland K. Roberts, Burton C. English, James A. Larson, Rebecca L. Cochran and Steven W. Martin

Evidence on the Amenity Value of Wetlands in a Rural Setting / Okmyung Bin and Stephen Polasky ...

Modeling Beef Quality Heterogeneity / Jayson L. Lusk and F. Bailey Norwood .

Estimating Indirect Production Functions with a More General Specification: An Application of the Lewbel Model / Christiana E. Hilmer and Matthew T. Holt ................ 61

Measuring the Impact of Externalities on College of Agriculture Teaching Evaluations / Ronald A. Fleming, Ernest F. Bazen, and Michael E. Wetzstein

Consumer Willingness to Pay for "Second-Generation" Genetically Engineered Products and the Role of Marketing Information/Matthew C. Rousu, Daniel C. Monchuk, Jason F.

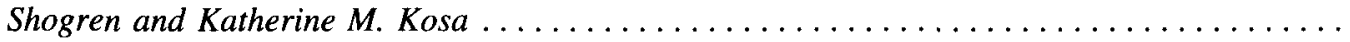

Exploring Horticultural Employees' Attitudes towards Their Jobs: A Qualitative Analysis Based on Herzberg's Theory of Job Satisfaction / Vera Bitsch and Michael Hogberg . . . . . . . . 659

Willingness to Pay for Information Programs about E-commerce: Results from a Convenience Sample of Rural Louisiana Businesses / Susan Watson, O. John Nwoha, Gary Kennedy, and

Effects of Federal Risk Management Programs on Optimal Acreage Allocation and Nitrogen Use in a Texas Cotton-Sorghum System / Sangtaek Seo, Paul D. Mitchell, and David J. Leatham

Willingness to Pay for Genetically Modified Oil, Cornflakes, and Salmon: Evidence from a U.S.

Telephone Survey / Naoya Kaneko and Wen S. Chern ...................... 701 